\title{
Correction to: Clinical feasibility and impact of fully automated multiparametric PET imaging using direct Patlak reconstruction: evaluation of 103 dynamic whole-body 18F-FDG PET/CT scans
}

\author{
André H. Dias ${ }^{1}$ - Mette F. Pedersen ${ }^{1} \cdot$ Helle Danielsen ${ }^{1} \cdot$ Ole L. Munk ${ }^{1,2} \cdot$ Lars C. Gormsen $^{1,2}$ \\ Published online: 13 February 2021 \\ (C) Springer-Verlag GmbH Germany, part of Springer Nature 2021
}

Correction to: Eur J Nucl Med Mol Imaging https://doi.org/10.1007/s00259-020-05007-2

There is an overlap problem with picture $2 \mathrm{a}$ and $2 \mathrm{~b}$ of the original article. There is also a minor issue with Table 3 which has caused for the first column to appear very wide and the second column to be too narrow.

The original article has been corrected.

Publisher's note Springer Nature remains neutral with regard to jurisdictional claims in published maps and institutional affiliations.

This article is part of the Topical Collection on Erratum.

The online version of the original article can be found at https://doi.org/ $10.1007 / \mathrm{s} 00259-020-05007-2$

Lars C. Gormsen

lars.christian.gormsen@clin.au.dk

1 Department of Nuclear Medicine \& PET Centre, Aarhus University Hospital, Palle Juul-Jensens Boulevard 165, DK-8200 Aarhus

N, Denmark

2 Department of Clinical Medicine, Aarhus University, Aarhus, Denmark 